\title{
Individuo y comunidad en la teología europea y en la teología de la liberación
}

\section{J.I. González Faus, Sant Cugat del Vallés, Barcelona. Centro de Reflexión Teológica, San Salvador.}

\section{Introducción. Para iluminar geográfica e históricamente el problema}

\section{Europa y América Latina}

Una reciente obra de antropologia teológica latinoamericana (la de J. Comblin) hace arrancar su estudio de la experiencia de las comunidades creyentes: "lo que los cristianos pueden ofrecer (sobre el hombre) es la vida y la práctica de sus comunidades."

En cambio, cualquiera de los tralados clásicos europeos sobre el mismo tema (Flick-Alszeghy, Ladaria, Panneberg... incluido mi reciente Proyecto de hermano) habla siempre del hombre considerado como individuo (aunque pretenda hablar de él estudiándolo a un nivel de abstracción que haga válidas sus afirnaciones para todos los hombres)!

No pretendernos valorar esta diferencia, pero sí considerarla como dato sintomb́rico. Occidente sigue siendo hijo (y a veces esclavo) del indivudualismo de la modemidad, caracterizada - como se ha dicho repetidas veces - por el "descubrimiento del sujeto." Lo novedoso de la teología latinoamericana es hasta qué grado la experiencia creyente y la vivencia espiritual son experiencias comunitarias, en su modo de realización, pero también muchas veces en su contenido.

Es cierto también que la teología europea ha sido consciente, en más de un momento, de esa limitación de sus planteamientos antropológicos: ya en los afios sesenta J.B. Metz lanz6 aquel grito progranático de "desprivatizar la fe," y la teologfa. Pero hay que reconocer igualmente que aquel programa sigue prác- 
ticamente incumplido en Europa: quizá no por falta de conciencia respecto a la importancia de la tarea, pero sí porque en las iglesias europeas no hay sujeto constituido capaz de realizarla. Y porque el marco cultural en que se hace la teología quizá rechaza ese programa más que exigirlo.

\section{La inestabilidad de la historia humana}

Esta anécdota ambiental, geográfica, nos introduce de lleno en la importancia y la dificultad del problema individuo-comunidad. Europa es hija de la filosofía griega, que vivió asombrada y torturada por la experiencia inconciliable de "lo uno y lo múltiple." Y eso que los griegos pensaban al ser como "ente," como cosa inerte. Cuando en la ilustración el ser pasa a scr pensado primariamente como persona, como conciencia de ser (Dasein), como un sujelo (y, en este sentido, como "único") el problema de lo uno y lo múluple se conviente en el problema de la multiplicidad de sujetos. Y el problema de las relaciones individuocomunidad parece plantearse como el enigma insoluble de una multuplicidad de absolutos.

Quizás por eso, Hegel pareció pensar que la historia humana se constituye por una serie de figuras diversas de relaciones individuo comunidad, y que cada época de equilibrio en esas relaciones viene seguida por otra época de desequilibrio en favor de uno de los dos polos, la cual se resuelve luego en el progreso hacia una nueva figura de equilibrio sicmpre incstable... A su vez, S. Freud dejó profundamente grabado en la conciencia de occidente que la comunidad establecida (la "cultura" en lenguaje freudiano), aunque sea necesaria para el individuo, sólo es posible mediante una dosis importante de "malestar" en él. Ese "malestar en la cultura" es intrínseco al hecho mismo de la cultura, y es diverso de otros malestares accidentales o supererogatorios que puedan provenir de las deformaciones o maldades de una cultura determinada.

Pero esto que decimos no es típico solamente de una determinada reflexión filosófica. La historia política de los hombres da testimonio también de este doble dato: por un lado la eficacia y esplendor de los "todos" sociales en los cuales el individuo estuvo oprimido, en la medida en que se consiguió hacerle tragar esta opresión (pensamos en el antiguo Egipto, en la Grecia de los esclavos e "ilotas", o en el Japón moderno...). Pero, por otro lado, la urágica grandeza humana que tiene en ciertos casos la rebelión del individuo (como en el magnífico drama de la Antígona de Sófocles).

$\mathrm{Y}$ sin embargo, esa indudable e impresionante grandeza humana arrastra a su vez un peligro de "anomía" y desintegración de los "lodos" sociales. De ahr la necesidad de redomesticar de nuevo al individuo, esta vez quizá ya no con la fuerza ni mediante la divinización de los poderes del "todo" (pues la grandeza de Antígona reside precisamante en su pérdida de miedo a la fuerza coactiva del todo), pero sí por medio de mecanismos más sutiles o más aceptables. Citemos algunos ejemplos de esos mecanismos: o por la falsificación del sentimiento patrio 
(que suele ser característica de todos los lascismos y todas las doctrinas de "seguridad nacional"); o bien por la domesticación del individuo a través de un consumo material loco e insaciable (alll donde esto sea posible); o bien por ambos factores a la vez...

Porque efectivamente, cuando la rebclión del individuo sobrepasa sus límites, y se convierte en individualismo, en autoafirmación exclusiva del yo, entonces la comunidad va volviéndose imposible, la violencia "carga" el ambiente como una tormenta próxima a descargar, y el antiguo problema teórico de "lo uno y lo múltiple" se convierte ahora en la mentira práctica por la que el individuo se apropia de "lo uno" en lugar de situarse en su verdad: en lo múliple. Así el individuo se identifica con el famoso título de Max Stimer (El Uno y su propiedad), y se arroga para sí mismo necesidad y absolutez. El hombre se convierte en "un lobo para el hombre," y la historia humana quedará definida como "lucha de clases" (en el mejor de los casos), o como "guerra de todos contra todos." No es extraño que las tesis de M. Stimer irritasen tanto a K. Marx porque, además, difícilmente pueden tener refulación "científica," y Marx sólo quería creer en este tipo de argumentos. Pero (quizás mejor que Marx) se puede contraponer a ellas esta otra tesis de la sabidurfa del antiguo oriente:

Y si uno ve una cosa egoísticamente, como si lo luera todo, independiente del Uno y de los muchos, entonces uno se halla en la oscuridad de la ignorancia (Bhagavad Gila 15).

Todos estas evocaciones introductorias (geográficas e históricas) quizás ayuden a plantear nuestro tema con todo su importancia y toda su envergadura.

\section{Datos de la fe cristiana}

\section{El Dios cristiano}

Es sorprendente, en todo el contexto anterior, la tajante afirmación cristiana de que la "personalidad" de Dios consiste en ser comunión de personas. Es sorprendente que el cristianismo haya mantenido esta profesión trinitaria de Dios como su tarjeta fundamental de identidad, por cuanto infinidad de veces la trinidad ha sido combatida por voces "razonables" que la consideran "absolutamente inútil" (caso de E. Kant), o por movimientos teológicopolíticos que defendían la "monarquía" de Dios como paradigma supremo de la monarquía individual de los emperadores (caso del arrianismo).

Es cierto que, en la misma teología cristiana, la doctrina de la trinidad ha oscilado siempre, insuperablemente, entre explicaciones que acentuaban más la unidad (por afán de salvar el monoteísmo bíblico, irrenunciable para un cristiano) y explicaciones que acentuaban más la pluralidad (por afán de salvar la identidad del Dios cristiano, que amenazaba con quedar absorbido por el Uno platónico o aristotélico). A pesar de ello queda siempre, como resto "sagrado" inaccesible a la 
razón humana, y como resumen de la doctrina cristiana sobre Dios, este doble dato; a) que las personas en Dios son, a la vez, diversas en sus "relaciones" entre sí y en sus "misiones" hacia los hombres; y b) pero también son consustanciales y coiguales, sin que la diversidad implique ningún tipo de "subordinacionismo." Y ninguna de estas dos afirmaciones es prioritaria respecto de la otra.

En este sentido, el misterio siempre inaccesible de Dios se convierte, sin dejar de ser Misterio Absoluto, en norte de la comprensión cristiana del hombre: "dime qué imagen de Dios tienes y te diré cuál es tu ideal de Hombre." Así se comprende aquel aparente desplante con que un patriarca de la Iglesia rusa respondió a la pregunta de un periodista acerca del programa político de la Iglesia: "El programa político de la Iglesia rusa es la trinidad."

\section{La obra de Dios en la historia}

Según el mensaje cristiano, ese modo de ser de Dios se transparenta en la historia humana. Se transparenta, aunque sólo de una manera emergente, en lucha contra la opacidad de la historia y contra la contradicción del pecado humano. Dios llama siempre a un pueblo y para que sea pueblo, o mejor. pueblo de Dios, lo que implica su instauración en la igualdad, la fraternidad y la justicia. Dios se revela como Aquél que hace un pueblo de lo que era "no-pueblo" ( $c f$. Os 2, 1-25; 1Pe 2, 10). Y la elección de personas particulares por Dios siempre es una elección "para los demás", no un privilegio particular que termine en el individuo elegido.

De acuerdo con esto, ya el Antiguo Testamento está atravesado por una dialéclica que afirma la virualidad comunitaria de todo aquello que es, en lo individual, auténtica calidad humana según Dios. Me estoy refiriendo a la célebre dialéctica bßlica de la "representación" o vicariedad, de la cual la teología occidental no consigue dar razón cumplida. Un solo justo en Sodoma podría redimir a toda la nación, el "resto" de Israel recrea la fidelidad de todo el pueblo, el Sicrvo de Yahvé sufre todo lo comunitario en su dolor personal y, por eso, "justifica a muchos" (cf. Is 53, 4-12). La pequeñez del pueblo escogido se explica porque no ha sido elegido por su grandeza particular, sino para ser luz e imán de todas las naciones; mientras que el pecado del pueblo consistirá en amar más una grandeza particular, competitiva, "como la tienen las otras naciones" (1Sam 8, 5), que su tarea de ser luz de todos los pueblos desde su pequeflez. Los intentos de rescatar una justificación teológica para la ambigua opción por la monarquía (en lo cual "no te rechazan a ti sino a Mí," según dirá Yahvé a Samuel: 1Sam 8,7), son intentos que discurren por la idea de una "calidad universal" del monarca el cual, precisamente por eso, sólo tiene sentido como rey en la medida en que sea vindicador de los pobres, de los indelensos sin voz, de los que no tienen y de los excluidos de la comunidad. Lo que Israel pide a Dios para su rey es que "defienda a los humildes del pueblo, socorra a los hijos del pobre y quebrante al explotador... que libre al pobre que clama y al afligido que no tiene protector, que se apiade del indigente y salve la vida de sus polres, porque la vida de los pobres es 
preciosa ante los ojos de Dios" (Sal 71, 4.12-14). Y lodo poder personal que no se defina y justifique por esta misión o que -como han sido casi todos los poderes individuales en la historia humana- sirva para quebrantar al pobre y apoyar al explotador, será siempre un "rechazo de Dios," un "no querer a Dios por rey" (1Sam 8,7), una prepotencia individual injustificada, que acaba desintegrándose como se desintegtó la monarquía en Israel. Pues ese poder se convierte entonces en lo que la Biblia llama "poder de la zarzas," es decir: en el poder de los peores, los cuales sólo acceden al poder porque la calidad de los buenos (del olivo, de la higuera o de la vid) consiste en que "no voy a renunciar a mis frutos que alegran a dioses y hombres para mecerme sobre los demás árboles" (cf. Jue 9, 7-15).

Este modo de obrar de Dios en la historia encuentra su culminación en Cristo que anuncia una paternidad de Dios mediada por el reino de la fratemidad humana, que sólo será rey "desde la cruz," y a quien competen todos los títulos veterotestamentarios que contienen esa dialéctica entre lo personal y lo comunitario: el de Siervo de Yahvé, el de Hijo del Hombre, etc. La resurreción, en cuanto exaltación de Jesús hasta la dimensión misma de Dios, implica su universalización e incluye así la resurrección de todos los hombres, convirtiendo a Jesús en primogénito y primicia de los que mueren (cf. Col 1,18 y 1 Cor 15,19 ).

\section{La comunión de lo santo o la huella de lo trascendente en la historia}

Esta teología de la "representación" culmina en el dogma cristiano de la comunión de lo santo. La communio sanctorum exige ser traducida, a la vez, en masculino y en neutro. Pero debe comenzar por ésta segunda traducción para incluir la primera: los santos están en comunión, porque la sanlidad misma de Dios es comunión. La "comunión de lo santo" expresa simplemente la comunitariedad, la fecundidad y la universalidad del Amor, que es Dios. Al profesarla, el creyente se atreve a esperar que puede justificarse por el don de la humanidad de los otros, que le pertenece por esa naturaleza comunitaria de lo santo. Se atrave también a esperar que si algo hay en él de fe, de esperanza y de amor sobrenalurales, servirá para justificar a todos aquellos que no creen y no aman: pues esa fe esa esperanza y ese amor no son exclusivamente suyos, sino que pertenecen a todos por la comunión de lo santo. Por esta razón, esa comunión de lo santo tiene un lugar específico en el credo, que conviene detallar un poco más: aparece junto a las notas de la Iglesia y junto al perdón de los pecados.

Aparece junto al perdón de los pecados porque, como explica Alberto Magno (uno de los grandes teólogos de la communio sanctorum), "sólo puede haber comunión allí donde desaparece lo que es propio y exclusivo, y esto es el pecado de cada cual." De este modo, el hombre que es pecador "tiene en los otros lo que le falta en si" (In III Sent, dist 24 B,art 6).

$\mathrm{Y}$ aparece tras las notas características de la Iglesia como declaración de ellas (hoy diriamos: como descripción de la "sacramentalidad de la Iglesia). Unidad, santidad, catolicidad y apostolicidad no son, en el fondo, nada más que comu- 
nión. Y esta comunión, que caracteriza a la Iglesia, es posible no sólo por la experiencia común creyente, sino también por el contenido mismo de esa experiencia de fe: que El santo es comunión.

Todo esto tendrá inmediatamente sus repercusiones prácticas en el imperativo dado a la Iglesia de estructurarse como comunión (koinonta) tal como veremos luego en el aparado 5 de este mismo capítulo. De momento limitémonos a señalar cómo de esa comunión de Lo Santo brota la comunión de "los santos" que, en un principio, se refírió a wodos los creyentes, pero que hoy puede dar verdadera razón del culto católico a los santos. Es una manera de expresar que los santos no son de ellos mismos, sino que son de lodo el pueblo cristiano y de todos los hombres, tal como se dijo con acierto en la canonización de Juana de Arco. Pero para eso es preciso que la Iglesia no se sienta tentada a canonizaciones que parezcan bendecir una particularidad de hecho excluyente (aunque sea la misma particularidad de los intereses de la jerarquía), sino que mantenga aquel esquema de justificación de la realeza israelita, y de Jesús, en su acercamiento a los marginados: que sólo se puede ser universal a partir y a través de la preferencia hacia los más excluidos. Ello obliga hoy a la Iglesia (si es que quiere parecer de veras sacramento de comunión) a buscar sus santos entre aquellos que trabajaron por "salvar al pobre que clamaba y al afligido que no tenía protector," entre aquellos que lucharon por "socorrer a los pobres y combatir al explotador" (Sal 71, citado). Esta es la fina intuición teológica que late tantas veces en el sentir de los fieles cuando espontáneamente canonizan a hombres como Mons. Romero. Y si esa canonización resulta incómoda para la jerarquía eclesística, eso será la llamada más seria a un examen ante Dios en el cual se pregunte si ella es efectivamente un "sacramento de la comunión," o más bien ha recaído en el mismo pecado de la monarquía israelita: porque tratar de tender el silencio sobre hombres como el arzobispo Romero, constituye una manipulación mucho mayor que la que puedan cometer con él los pobres de la tierra que lo reivindican como suyo.

\section{La concepción cristiana de la fe}

Finalmente, esta comprensión uni-trinitaria de Dios culmina en la teología cristiana de la fe. Porque la fe en Dios sólo es posible, para el cristiano, gracias al ser comunitario de Dios, en virtud del cual Dios puede ser no sólo el término inaccesible de la fe (Padre), sino también la donación de ese térnino inaccesible por cuanto Dios es, a la vez, el mediador desde nosotros hacia ese Padre absolutamente Trascendente (Hijo o Palabra), y el impulso mismo que recorre e interioriza esa mediación en nosotros (Espíritu).

Por esta razón, la fe personal posee a la vez una estructura igualmente comunitaria porque, para la Palabra y el Espíritu de Dios, no vale ya esa separación propia de lo creado, y por la que lo más personal parece menos comunitario y viceversa: el Hijo es Recapitulador universal, y el Espíritu es personificador de los muchos, derramado sobre toda carne como "alma" del cuerpo de los creyentes. En las iglesias cristianas han surgido a veces discusiones sobre el modo de recitar 
la proclamación de fe que solemos llamar "credo:" sobre si debía decirse "creo" o "creemos." Los peligros de cada opción (una fe gregaria sin riesgo personal o una fe sola, como mérito personal) son comprensibles y, por eso, los cristianos deberían saber combinar ambas fómulas en sus profesiones creyentes. Pero, si la ley del orar tienen algo de ley para el creer, no estaría de más recordar que, cuando Jesús nos enseña a orar, propone una oración en la cual siempre se habla de nuestro y nosotros, y nunca de yo o mío (Padre nuestro, pan nuestro, venga a nosotros, perdónanos como nosotros, no nos dejes, libranos...). Este detalle debe entenderse desde la convicción jesuánica de que la oración es el acto más íntimo de la persona. Pero es que el mismo Espíritu que clama en nosotros abba (Padre: cf. Gal 4,6 ) es el que clama ante los otros: "hermano." Ante cada hombre y, sobre todo, ante el peor tratado como hombre.

De aquí se seguirá eso que J.B. Metz califica como "la idea totalmente simple pero, a pesar de todo, no evidente en los medios teológicos ordinarios, de que el sujeto del acto de fe según los datos bíblico-cristianos, no es el yo singular en su carácter de sujeto aislado, sino el yo en su carácter originario intersubjetivo, en su condición de hermano'..." Hasta tal punto que el impulso de aislamiento de la fe será siempre, para Metz, impulso de la "concupiscencia," mientras que la intersubjelividad "puede ser tratada como una determinación esencial, si no la determinación central del sujeto creyente cristiano." Lo que significa para nuestro autor que "no somos salvados en consideración de nuestra fe sino sólo en consideración de nuestros hermanos y, a través de ellos, de Dios, en quien está escondida la última pluralidad existencial y división de nuestra existencia creyente (Col 3, 3)."2

Pero si la pluralidad y división de nuestra existencia creyente está de ese modo "escondida en Dios," esto marca para la comunidad de creyentes - como hemos dicho hace poco- la más decisiva de las tareas de su misión ante el mundo: la tarea de ser efectivamente sacramento de la comunión entre los hombres, en un mundo marcado por la división, la diferencia y la hostilidad. Este es el último punto que nos queda por ver.

\section{La noción cristiana de "comunión" (koinonía)}

Derivada de su concepción de Dios y del actuar de Dios que se recibe en la fe, la noción de koinonía es una de las más presentes en todos los escritos del Nuevo Testamento, con infinidad de variantes expresivas que aquí no es posible analizar. Uno de los componentes característicos de este concepto es el de ser una comunión en la diversidad; y una diversidad que tiene como complemento la primacía de lo más débil o de lo menos aparente, porque es una diversidad sólo de funciones, pero no de dignidades o valores personales. En Cristo Jesús no hay ni varon ni mujer, ni esclavo ni seffor, etc.

La imagen del cuerpo, estirada hasta la alegoría de que tratamos con más cuidado y más mirarniento lo que parece más débil o menos digno, y que cuando 
sufre cualquier miembro sufren lodos con él, funciona como visibilización elemental de esa comunión cristiana (cf. 1Cor 12,12ss). La koinonía se contrapone tanto a la masificación como a la uniformidad. En ella no hay desintegración, pero tampoco autoritarismo porque -estirando la alegoría del cuerpo- es "el espíritu" lo que la crea, y no algún miembro preeminente. La unidad del cuerpo es tal en el seno, no sólo de la diversidad, sino a veces de la tensión.

En ese contexto se convierte en objeto de recomendación para el cristiano individual la orientación servicial y humilde de su vida: precisamente porque la cerrazón en lo individual (o el amor propio) es el pecado, hay que presionarla hasta el otro extremo (cn una especie de agere contra ignaciano), tratando de convertirla en servicio, para que así logre ser comunión: "considerando superiores a los demás (Fil 2, 3), "teniéndose a uno mismo por servidor de todos" (cf. 1Cor 9, 19) de modo que "no busque su interés sino el ajeno" (1Cor 10,14), etc. El individuo, que puede experimentar muchas veces una sensación de muerte en la práclica del servicio, resucitará transformado cuando, a través del servicio, llegue a la experiencia de comunión.

Finalmente, esta koinonía tendrá, para el primitivo cristianismo, dos consecuencias ya casi perdidas que la teologia de la liberación intenta recuperar, y que merece la pena subrayar ahora.

La primera es una extensión hasta lo material de la vida. Precisamente porque lo "espiritual" es intrinsecamente comunitario, es de todos como veíamos hace un momento, el cristiano se siente llamado a que eso se refleje también en lo material, dado que el Espfritu de Dios no es excluyente, sino transformador de lo material. "Ten todo en común con tus hermanos y a nada llames tuyo; pues si tienes una koinonia en los bienes inmortales, cuánto más en los perecedores." Este es un consejo repetido en varios textos de la primitiva predicación cristiana, y que se refleja en las conocidas descripciones del libro de los Hechos sobre la praxis de la primitiva comunidad. Es importante destacar el "cuánto más" con que se arguye en dichos textos: si el Espíritu (que es lo más personal que existir puede), es intrínsecamente comunitario, "cuánto más lo material" que en modo alguno tiene calidad personal. De acuerdo con esto, más que de una simple "función social" de la propiedad, o incluso más que de una "hipoteca social" (término indudablemente más fuerte), la Iglesia primera habla de una finalidad social y de una verdad social de la propiedad

La segunda consecuencia en que se actúa la noción de koinonía es el mandamiento tajante de invertir la autoridad en servicio (y no simplemente por la intensión invisible, sino por sus modos visibles de ejercicio). El poder personal, precisamente porque puede ser la máxima afirmación del individuo y la mayor negación de su polo comunitario, es, para el Nuevo Testamento, uno de los mayores pecados. Como por otra parte la autoridad es indispensable en cualquier sociedad humana (aunque sea a la vez insuficiente), y como la Iglesia no está eximida de las leyes de la historia, el nuevo Testamento retoma el consejo de Jesús (Lc 
$22,14-27$ ) y la praxis de Jesús (cuya eksousía "no era como la de los escribas y fariscos;" cf. Mc 1,22 y 10,45), inviriendo la autoridad en servicio. Se quiere decir con ello que no es el poder el que, por el hecho de ser poder, engloba y representa a todos los hombres.

$Y$ de aquí surge un úlimo elemento decisivo para la visión cristiana del hombre, y del hombre individuo-comunidad. El concepto que, en el Nuevo Testamento, más se contrapone al de koinonía podria ser el de pleoneksia (avidez, áán de más, "deseo"). Se trata de un concepto combalido repctidas veces en los escritos neotestamentarios y definido incluso como pura y simple "idolatria" ( $c f$. Ef 5 , 5; Col 3, 5). El Nuevo Testamento conoce, por tanto, la misma sospecha de las grandes religiones del oriente ante el deseo como raíz de todos los males. Pero la respuesta neotestamentaria a este drama no se formula nunca como una simple muerte $o$ aniquilación del deseo, en alguna forma de apatia o nirvana, sino como una auténtica transformación del deseo en solidaridad y en comunión no posesiva. Esta transformación es evidentemente imposible para el hombre. Pero el Nuevo Testamento la cree posible por la acción del Espíitu de Dios "derramado en el corazón" del hombre (cf., vg. Rom 5, 5). Ese parece ser uno de los puntos más característicos de la fe cristiana en el tema de las relaciones individuo-comunidad.

\section{Cómo resuenan estos datos de la fe en la teología europea y en la teología de la liberación}

La tcologia de la libcración ha manifestado mayor capacidad para integrar en su reflexión todos estos dalos de las fuentes cristianas de lo que ha sabido hacer la teología en el primer mundo. Este es probablemente uno de los factores que explican su inesperada resonancia mundial, a pesar de la pobreza de medios de producción o distribución, y a pesar de las resistencias interesadas que son ya conocidas.

Es lógico pensar que esa mayor facilidad se deba a las diversas situaciones socioculturales aludidas al comienzo de este artículo. Por ello se hace preciso ahora examinarlas un poco más detenidamente, sobre lodo porque sus trayectorias no dejan de ser paradójicas cuando se las mira de cerca: se diria que recorren un camino de afirmación de la propia vida que acaba perdiéndola, y otro camino inverso que salva la propia vida al haberla perdido (cf. Mc 8, 35).

\section{El círculo vicioso del primer mundo}

La paradoja evocada se manifiesta en el hecho de que, en la occidente individualista, es precisamente el individuo lo que se siente más amenazado e insatisfecho. Como si en el primer mundo se cumpliera uno de esos castigos bíblicos de Dios que consiste en "entregar a los hombres a sus propios deseos," occidente experimenta hoy que su cultura de afimación incondicional del individuo ha ido dejando a éste en manos de su propia soledad; que sus hombres educados en el valor del egoísmo y la "autoconservación" han acabo por conocer la incomu- 
nicación; que su recurso ideológico al enmascaramiento de la muerte individual ha acabado por producir individuos secretamente angustiados por una verdadera neurosis de salud, y que su sistema montado para defender a toda costa privilegios individuales por encima de necesidades comunitarias, ha dejado a los individuos solos y empequeñecidos frente a una macroestructura que los aplasta y pareciera que va a llevarlos hasta donde ellos no querrían: hasta su posible aniquilación, a manos de la destrucción nuclear, la depauperación ecológica o la asfixia del supercontrol informático.

En este sentido, hay que conceder que es legítima la preocupación individualista que manifiestan muchas obras de teología del primer mundo. Pero hay que añadir que la situación descrita puede llevar a buscar en la fe, o en el ámbito más impreciso de "lo religioso," unas desesperadas salidas indivualistas que se convierten, en realidad, en simples evasiones o huídas hacia adelante. Este lipo de soluciones quizás acabe volviendo a los hombres más crédulos pero, desde luego, no los volverá más creyentes. Y es otra vez mérito innegable de J.B. Metz el haber abierto los ojos ante esta forma de "religión burguesa" y haber señalado al mundo nordatlántico la urgente necesidad de superarla. En cambio, Ia experiencia de creyentes del primer mundo, que han vivido en el sur tercermundista, se conviere en punto de referencia decisivo para mostrar que la solución a los "males del individuo," en el norte, no puede venir de una intensificación de ese círculo vicioso de las reivindicaciones individuales, sino que ha de provenir de alguna ruptura dolorosa de dicho círculo.

$Y$ esto hace que el planteamiento de los problemas del tercer mundo en el primero, así como la atención a ellos, no puedan ser desautorizados rápidamente como simple "tercermundismo," que es la coartada postrema que últimamente ha comenzado a utilizarse en occidente. Aunque las soluciones no pueden ser acríticamente trasplantadas, los problemas constituyen una interpelación a cambiar todo un sistema de vida que no solamente es corresponsable de la situación infrahumana del tercer mundo ( $y$ requiere la conversión del primero para que pueda ser cambiada esa situación), sino que, además, se convierte en una insuperable trampa deshumanizadora para el mismo primer mundo.

Y al citar este círculo vicioso del mundo nordatlántico, que parece ir del individualismo a la decepción del individuo, se hace inevitable decir una palabra sobre el intento más serio y más rico de supcración de ese círculo entrópico, que quizás está constituido por la obra de Marcel Légaut. El programa de ese intento quizás podría formularse así: redimir al individuo de su insignificancia, enseñándole a ser uno mismo (cf. El hombre en busca de su humanidad; Creer en la Iglesia del futuro; Devenir soi). No es fácil en una breve página valorar la obra de Légaut. Pero me gustaría señalar al menos tres cosas: su mérito, su unilateralidad y su peligro.

En primer lugar su mérito. En Légaut se ha producido una auténtica redención de la espiritualidad. Mueno Rahner, quizás sea él él único autor que abre camino, 
que transmite verdad y que insula vida. El único maestro que "habla con autoridad y no como los escribas y fariseos del sistema." Este autor, que no cita desesperadamente a nadie, que procede del campo de las ciencias matemáticas, y cuyos escritos no pretenden rehabilitar a la teología en el foro de la universidad, sino en el hondón del corazón humano, no se presenta con otras razones teológicas más que éstas: la verdad de la expericncia humana frente al doctrinarismo seguro; el camino hacia la autenticidad humana frente al gregarismo infiel; y la vida de la interioridad humana frente a la superficialidad religiosa. Nadie como él, y quizás sin quererlo, ha sabido volver tan honda y an seria la categoría de "adoración" en un mundo religioso donde con frecuencia se toma el nombre de Dios banalmente en vano. De ahí que, sobre todo en los hombres combatidos, o sacudidos por la duda, la decepción y el abandono, Légaut deja más huella y obtiene más audiencia que cualquier palabra eclesiástica "oficial."

Era necesario decir lo anterior para poder agregar, en segundo lugar, su unilateralidad, la cual radica en el carácter mancamente individual de su espiritualidad. En Jesús y en el cristianismo sólo parece encontrar Légaut una llamada a cada persona a la fidelidad a sí mismo, a los tesoros, desconocidos para cada cual, de la "vida interior." La categoría del "reino de Dios," la buena noticia para los pobres, o la constante referencia que para Jesús suponen "los suyos" o "su pueblo" (y que son rasgos muy puestos de relieve en la tcología de la liberación), están totalmente ausentes de Légaut, no sólo a la hora de configurar su pensamiento, sino incluso de recibir una alusión o una mención. Sus referencias al otro tienen lugar casi siempre en el modo de una relación de yo a tú: el amor, la paternidad, y la figura del maestro, o comunidades muy pequeñas de personas espiritualmente afines. La dimensión del pueblo, de la comunidad de los diferentes, está ausente del todo y sólo aparece (como polo de referencia inevilablemente implícito por la naturaleza del tema) cuando el autor trata de la autoridad y critica, con razón, muchas de sus formas de ejercicio. Légaut insiste con frecuencia, y también con razón, en esa "soledad última" del hombre, y más aún del hombre "espiritual." Pero parece desconocer por completo que esa soledad puede ir acompañada (quizás no al nivel de los contenidos experienciales, pero sí al nivel de las experiencias de sentido) con la experiencia de la comunidad, de la comunión con los sencillos, de la posibilidad de "dar vida" y de ser evangelizado por los pobres. Frente a aquello de Jesús de "dar la vida por los hermanos" aquí parece estar sólo el vivir la vida para encontrarse consigo mismo.

Y linalmente, los peligros de esa unilateralidad. Dicho ahora con cierta crudeza cabría hablar del peligro de degenerar en un cristianismo aristocrático, el cual, a su vez, será puerta casi inevitable para un gnosticismo en el que "el hombre espiritual" sea una expresión con más sentido gnóstico que significado paulino, es decir, aun sin querer, se parecerá más al hombre que está por encima de los demás que al hombre para los demás. Por eso, todo lo que la fe tiene inevilablemente de estructura (por lo que ticne necesariamente de comunidad) se convertirá para este hombre en superestructura, es decir, ya no será lazo de co- 
munión, sino armadura inútil de la cual la vida interior invitará a desprenderse. Y tal hombre se abrirá a una forma de fe que, de tan desnuda que querrá ser, amenazará sólo con estar sólo vestida de uno mismo.

Cieramente, las formulaciones de M. Légaut, por su linura y por su dclicade2a, nunca llegan a expresar todo eso. Pero, en mi opinión, esc es el pcligro casi fatal que late en todas ellas, a menos que, sin desecharlas en absoluto, sc las complemente con igual intensidad con el otro polo: cl polo comunitario de la lc y de la persona que es el que parece ir emergiendo en la icología de América Latina.

\section{La "obra grande de Dios" porque "ha mirado la humillación" del mundo esclavo}

De forma igualmente paradojica, hay que decir que lo que ha vuelto a la teología de la liberación más sensible a los rasgos anteriormente expuestos del mensaje cristiano no ha sido precisamente una siluación de comunidad "realizada." Pues es evidente que América Latina no vive esa situación, aunque tampoco viva la cultura nordatlántica de una comunidad "olvidada," sino más bien una situación dolorosa de comunidad "pisoteada" y destrozada. La clamorosa presencia de grandes masas depauperadas, de diferencias insultantes en niveles de vida, tan distantes en posibilidades como cercanas en el espacio, la realidad de millones de refugiados, de familias con varios miembros desaparecidos..., todo eso constituye un dato que en América Latina no puede ser ocultado, porque su sujeto no son pequeñas minorías despreciables, sino las grandes masas del continente. Este dato permite una captación más inmediata de aquello que Medellín y Puebla calificaron como pecado estructural, y que Puebla deline de esta manera:

El pecado, fuerza de ruptura, obstaculiza permanentemente el crecimiento en el amor y la comunión, tanto desde el corazón de los hombres como desde las diversas estructuras por ellos creadas, en las cuales el pecado de sus autores ha impreso su huella destructora (n. 281).

Este texto sitúa el crecimiento humano en lo comunitario (el amor y la comunicación), concibe el pecado como algo individualista (como "fuerza de ruptura" de ese crecimiento), y ubica dicha fuerza no sólo en la interioridad de los individuos, sino en los sistemas de convivencia por ellos creados. Semejante manera de concebir se hace más comprensible en una comunidad coma la latinoamericana, que ha experimentado la falsificación de todas las mediaciones comunitarias (nación, clase, ciudad, Iglesia...) y la negación de todas las alteridades con las cuales la comunidad se construye (cultural, racial, sexual...). Esa falsificación y esa negación son, en definitiva, las que luego originan esas masas en situación de pobreza extrema o casi-extrema. Pero son también las que pueden provocar una conciencia lúcida de sí mismas y una conversión hacia la recuperación de las mediaciones y 
el respeto a las alteridades. Pucde que valga la pena desarrollar un poco más todo cste punto.

\subsection{La "humillación" de las mediaciones comunitarias falsea- das}

Entrc las mediaciones comunitarias falscadas no podemos contentamos con evocar sólo la noción clásica de las "clases sociales," las cuales en América Latina viven más intensamente y más simplificadamente esa situación de agresión-de-clase que, tradicionalmente, suele conocerce como "lucha" de clases. Además de eso, conviene evocar la falsificación de las comunidades nacionales por esa doctrina anticristiana de la "seguridad nacional," la cual sólo es un apéndice camuflado de otra doctrina de la scguridad "imperial."

La doctrina de la "seguridad nacional" destroza la misma comunidad nacional al presuponer que sólo un reducido tanto por ciento de la nación tiene derecho a ser considerado como tal, y tiene además derecho a defender esa apropiación, incluso violentamente. En este contexto, es imposible tratar el tema individuocomunidad en América Latina, sin decir una palabra sobrecogida ante la realidad atroz de los ejércitos latinoamericanos, puestos al servicio de esa seguridad nacional desde Argentina y Chile hasta El Salvador y Guatemala. Si la institución misma del ejército parece necesaria a algunos por la necesidad de concentrar y controlar las fuerzas requeridas para la defensa, mientras les resulta cuestionable a otros porque da lugar a tentaciones invencibles de poder, y porque refuerza indirectamente los círculos viciosos (y cada vez más amenazadores) de la violencia, en América Latina ya no cabe oscilar en esa ambigüedad, que se ha resuelto fatalmente en favor de la segunda hipótesis. Apenas habrá un ejército latinoamericano que no haya traicionado profundamente a su propio pueblo al cual debía servir, poniéndose al servicio de los intereses de una minoría privilegiada y de un imperio extcrior, los cuales - a través de ellos-se han convertido literalmente en genocidas. Si hay alguna imagen que encarne la antítesis de todo cuanto veiamos en el apartado II, 2 sobre el poder regio en el antiguo Israel, es la de casi todos los ejércitos latinoamericanos: "ensaffarse con el pobre que suplica y con el alligido que no tiene protector; alinearse con los poderes y machacar para ellos la vida de los pobres, que no vale nada ante sus ojos"... (cf. el Sal 71, ya citado). El grito angustiado que le costó la vida al arzobispo Romero ("iSon de nuestro mismo pueblo! ¡Malan a sus mismos hermanos! Y ante la orden de un hombre que ordena matar, siempre debe prevalecer la palabra de Dios que dice: no matar. Por eso, en el nombre de Dios, yo les pido, les mando, les ordeno: cese la represión"), estas palabras no eran un grito casual ni extemporáneo, sino expresión de una angustia más que justificada, ante las consecuencias de esa ideología llamada "de la seguridad nacional," a la que Puebla había condenado como anticristiana, aunque luego, una imprevista manipulación secreta del texto votado por los obispos, difuminó claramente esa condena. La reacción asesina que desataron fue la mejor prueba de ello. 
Y siguiendo nuestra enumeración, podemos evocar también la falsificación de las comunidades urbanas que, ел América Latina, ha tenido lugar mediante la aparición súbila de las más inhumanas megápolis (a la vez mayores y peores que las más grandes capilales europeas cuyos errores han multiplicado), las cuales han aparecido precipitadamente, antes de tiempo, sin ninguna posibilidad de asimilación sana para una sociedad mayorilariamente agrícola, y en la cual no se había apenas producido (o se ha producido con una rapidez inasimilable, tanto en el aspecto material, urbano, como en el cultural o cívico) el lento proceso de la conliguración de clases medias y de la aparición de pequeñas y medianas ciudades, que caracteriź́ a la Europa de los siglos XIII y XIV. Este insano y alocado estallido de las megápolis descomunales, debido casi exclusivamente a intereses económicos foráneos, parece ser otro de los factores innegables que amontonan y hacen más visible la miseria y la impotencia.

\subsection{La "humillación" de las alteridades despreciadas}

Junto a ese falseamicnto de la mediaciones comunitarias, hemos hablado también de un desprecio de las "alteridades." La experiencia pasiva de ese desprecio marca primero el nacimiento y luego la historia de los países lationamericanos, cuyos habilantes originarios indígenas y cuyas culturas autóctonas sintieron ignorada su identidad y su dignidad humana por los conquistadores, a pesar de la defensa heroica y admirable de toda una generación de obispos y misioneros (o mejor, de una parte de ellos, abandonados también -como escribiría Mons. Casaldáliga- "por sus propios hermanos de báculo y de mesa"). Pueblos, individuos y culturas vieron negada su condición humana, para poder así ser "legítimamente" conquistados y sometidos a esclavitud y a encomienda o vasallaje.

Cabe enumerar asimismo otras experiencias anticomunitarias de negación de alteridad. Junto a la altcridad del indio, la alteridad de la mujer, estructural y personalmente pisoteada por el célebre machismo latinoamericano, todavía poderoso. O la propia alteridad cultural, sometida a una colonización táctica europea o norteamericana, y obligada a una mímesis estéril: un europeo sólo debería sentir vergulenza cuando ve que anuncios de televisión, en América Latina, utilizan el reclamo de lo "europeo" más o menos como en Europa se recurre al señuelo sexual en la publicidad...

De este modo, la situación latinoamericana parece romper aquel esquema clásico hegeliano-marxista, que habla de un primer estadio (o "tesis") de comunismo "grosero," el cual se ve contradicho más tarde por otro estadio de individualismo absoluto, para quedar luego subsumidos ambos en la síntesis de un comunismo perfecto o una comunidad realizada, cuya plena realización es a la vez la plena realización de cada uno de sus miembros. En todo caso, en América Latina parece haberse pasado del "comunismo groscro" a la comunidad destrozada. ( $Y$ no es este el momento de discutir si las causas de ese destrozo son exclusivamente exteriores, como afiman los lenguajes de "imperialismo económico," "tcoría de la 
dependencia," etc, o si son sólo interiores, como pretenden los denegadores de esos lenguajes. Como suele ocurrir siempre, hay que pensar más bien en una interacción de ambos factores).

Lo que sí importa comentar es que, precisamente en esa siluación de comunidad destrozada, es donde han ido naciendo y recreándose en América Latina, experiencias de reconquista de lo comunitario, que tienen una seriedad y una intensidad difícil de concebir desde el mundo desarrollado.

Aunque aquí hemos de ceñimos a los aspectos teológicos del terna, será bueno dar por supuesto que dicha teología ha venido preparada por verdaderos precursores, o por "signos de los tiempos" que la teología latinoarnericana ha sabido leer. Para que no caiga en el olvido puede ser bueno evocar, como el primero de ellos, el gesto del presidente de Costa Rica, Figueres Ferrer, aboliendo el ejército ya en 1948 y convirtiendo esa supresión en mandato constitucional. Gesto aislado, utópico, "inviable," pero del cual se ha escrito, casi cuarenta años después, que ha servido para acostumbrar a algunos a la idea de que "no tener ejército era una bendición del Scñor." Y ya más cerca de nosolros, es necesario invocar la reconquista de un lugar de privilegio en la literalura universal, llevada a cabo por la reciente novelística latinoamericana casi en los mismos momentos en que nacía la teologla de la liberación. Estos y otros pequeños "milagros" o signos, han sabido reconocerlos muchos ojos creyentes como señales del Espíritu que anunciaban una venida del Señor para América Latina. No es casual, por tanto, si la obra que ha dado nombre a toda la corriente teológica (la Teología de la liberación de G. Gutiérrez) se abre con una larga cita del novelista J.M. Arguedas; ni si Pedro Trigo ha dedicado buena parte de su producción teológica a comentar la novelística latinoamericana recicnte. La comunidad con los pobres abre así a un reencuentro con la identidad -y la comunidad- latinoamericana.

Es en este contexto donde han ido naciendo importantes experiencias comunitarias creyentes, que suelen polarizarse alrededor de las llamadas "comunidades de base," y que no deben ser milificadas puesto que son todavía frágiles y amenazadas como toda vida naciente. Pero de las que sí cabe decir que el Espíritu de Dios ha aleteado entre ellas mucho más verazmente que entre los intentos primermundistas de "renovación espiritual," los cuales han derivado con frecuencia hacia espiritualismos irreales o hacia "docetismos" comunitarios, o se han mostrado mucho más sensibles hacia lo individual del "don de lenguas" que hacia lo comunilario de la "profecía," para decirlo con el mismo lenguaje de Pablo ("el que tiene don de lenguas se consuruye él solo, mientras que el que tiene don de profecía construye la comunidad," of. 1Cor 14,4). Aquí cabe aplicar los criterios de discemimicnto del mismo Pablo: mejor carisma es el que más comunidad puede construir, no sólo hacia dentro (cf, ibid., 14, 5ss), sino también hacia afuera (ibid., 14,24ss).

Quizás cabe sospechar, por tanio, y hasta decir en voz baja, que, en esas experiencias de las comunidades latinoamericanas, se han cumplido aquellas palabras de la oración de Jesús, cuando daba gracias al Padre porque comunica los secretos 
de su reino a los sencillos y no a los sabios y poderosos. Posiblemente, todos los teólogos de la liberación estarán de acuerdo no sólo en que (como hacía J. Comblin y evocábamos al comienzo de este arlículo) su rellexión teológica sobre el hombre no puede prescindir de la experiencia de las comunidades, sino sobre todo en que la vida misma y la existencia de esas comunidades es en realidad más importante que la misma teología de la liberación. En ellas se ha dado una primera reconstrucción de las mediaciones falseadas, desde la experiencia creyente. Y, junto con ésta, se ha dado otra profunda experiencia creyente de afirmación de la alteridad; pues es la alteridad máxima, del más pobre, la que se intenta respetar y afirmar allí: "cuando el pobre crea en el pobre construiremos la comunidad" (Misa salvadoreña). No es por eso extraño que, a propósito de ellas, se haya hablado de una verdadera "eclesiogénesis:" de un "reinventar la Iglesia" por las comunidades de base (L. Boff). O se haya hablado de una "resurreción de la verdadera Iglesia" (Jon Sobrino). Y esto parece que puede alirmarse ya, a pesar de los grandes problemas que quedan pendientes, para la praxis y para la teología.

Más aún, todo lo anterior puede ser afirmado aun reconociendo, por otra parte, que no es total, ni es lo mayoritario en las iglesias y en la teología de América Latina. Pero sí que es, en cambio, lo más característico y lo más fuerte.

Es muy posible que no sea lo mayoritario, porque una buena parte de esas iglesias, de sus jerarquías y de su producción teológica, se resiste aún a la transformación descrita de resucitar desde la muerte, y prefiere mantener la siluación "colonial," tanto para la teología como para la vida de la Iglesia. Esta orientación goza además del apoyo y de mayor fuerza de muchas instituciones "del centro." Pero en ella se reflejan los riesgos clásicos de todas las siluaciones "coloniales:" copiar casi todos los defectos de la metrópoli, y casi ninguna de sus virtudes. Y este carácter emergente, minoritario o, al menos, no total, es reconocido por los mismos representantes de la teologia de la liberación:

No todas las iglesias latinoamericanas están en condiciones de interpelar a nadie. Muchas de ellas deben ser interpeladas porque dejan mucho que descar. No existe la Iglesia latinoamericana como una Iglesia santa que pueda despertar al resto de las iglesias de su suefio religioso o dogmatico. ${ }^{3}$

Pero, aun no siendo todavía mayoritario, si que puede afirmarse que el proceso de conversión anteriormente descrito es, a la vez, lo más fuerte y lo más característico de América Latina. Allf se ha producido una sensación innegable de recuperación de identidad: y no es nada casual si la teología de la liberación ha sido calificada desde sus comienzos como "teologia latinoamericana de la liberación." Y ello a pesar de tres aparentes razones en contra. A pesar de que esos comienzos eran todavía muy oscilantes y muy dependientes, de modo que no han ido ganando su identidad hasta que aquellas reflexiones de los inicios se han ido bañando en la vida y en el sufrimiento del pueblo creyente latinoamericano. A pesar también de que la calidad teológica de la categoría "liberación" trasciende las fronteras de lo 
latinoamericano y es, en realidad, universal (católica) y cristiana y úpicamente neolestamentaria. Y a pesar, finalmente, de que en América Latina hay otras teologías y otros modos de vivir la fe, los cuales, sin embargo, han carecido de calidad y de identidad suficientes como para hacer abortar lo que el Espíritu iba haciendo nacer en América Latina, con su discreta forma de actuar, siempre necesitada de discernimiento y siempre fácil de negar, por cuanto actúa "entre el caos y las aguas" ( $c f$. Gen 1,2). Y repilo: porque han carecido de calidad y de identidad suficientes; no porque no lo hayan intentado con las razones de la fuerza de la manipulación, mucho más que con la fuerza de la verdad y de la transparencia. Pero en América Latina ha vuelto a ser verdad que "los torrentes no pudieron extinguir la caridad" (Cant 8, 7). Y por eso ha acabado triunfando aquel pronóstico de Gamaliel en el libro de los Hechos: "dejen en paz a estos hombres, porque si sus planes y su actividad son cosa de los hombres, fracasarán; pero si son cosa de Dios no lograrán suprimirlos, y se exponen a luchar contra Dios" (Hch 5, 3339).

De aquí debería aprender la teología latinoamericana, en sus horas aún agónicas y aún difíciles, que si efectivamente nace movida por el Espíritu de Dios, su mayor enemigo no estará nunca en los ataques de fuera y en los sufrimientos causados desde fuera o en las contradicciones que siempre desala todo paso de Dios por la historia. Sino más bien en la propia tentación de infidelidad que siempre sacude y amenaza a los elegidos por Dios.

\section{Algunas consecuencias}

Tras esta rápida reflexión de nuestros capílulos II y III sobre las fuentes de la fe cristiana, y sobre su resonancia en la vida de las iglesias cristianas de hoy, es posible regresar ya a lo central de nuestro tema, y extraer algunas ensefianzas más concretas. Vamos a presentarlas siguiendo la dirección marcada por la asamblea de Puebla, cuando busca el verdadero equilibrio entre lo individual y lo comunitario distanciándose por igual de wodo liberalismo y de todo colectivismo. Pues ambos fracasan en la sintesis individuo-comunidad porque son dos formas de materialismo autocentrado, que se cierran a lo espiritual.

\section{Para una superación comunitaria del individualismo norda- tlántico}

El llamado primer mundo debe destruir el mito sobre el cual se asienta, el mito de la universalidad de la razón individual y de la liberad individual. Razón y libertad pueden ser legíimas, pero no son universales. En cambio, según el inconsciente cultural del primer mundo, la razón sería universal por su poder de acceso a la naturaleza misma de la realidad; y la libertad sería universal porque la naturaleza armónica de lo real aclúa como una "mano invisible" que armoniza todos los egoísmos individuales en la forma de un servicio al bien común.

Ambos presupuesios han entrado hoy en crisis en el mismo mundo desarrollado, si bien con la crisis viene dada también la posibilidad de su redención. Las 
pavorosas experiencias de irracionalidad de la razón, y de posibilidades esclavizadoras de la libertad ( que se manifiestan en la cada vez más hiriente imposibilidad de la convivencia), han ido abriendo camino a categorías como la del "diálogo" (en sentido no meramente personal o políico," sino filosofico) o la "razón comunicaliva," etc. El ocaso de la modernidad (que es sobre todo el ocaso de la razón occidental) podría hallar su mejor salida - frente a todos los desencantos "postmodemos"- en aquellos versos de Hoblderlin que solía citar el filósofo M. Heidegger: jetzt dass wir ein Gespräch sind (ahora que somos un diálogo). J. Habermas o K. Apel deberían convertirse en nombres más significativos para la teología de lo que han sido hasta ahora.

Pero si esta razón dialogal no ha de quedar presa de un nuevo "pecado de origen" que la falsifique, como le ocurrió a la "razón universal" de la ilustración, no se debería hablar de clla sin subrayar inmediatamente las condiciones que le señalan sus promotores: el diálogo no será verdaderamente tal, y se falseará a sí mismo, a menos que intente ejercerse en unas condiciones lo más perfectas posibles de comunicación y de igualdad. Pero precisamente esta condición es la que resulta enormemente difícil de cumplir en el mundo desarrollado, donde la igualdad se halla reducida a una formalidad abstracta que sirve para consagrar infinidad de desigualdades reales.

Si esto es así, entonces la razón dialogal, o el empeño por crear consenso y convivencia en situaciones que estructuralmente no la posibilitan, deberá hacer un esfuerzo supletorio por incorporar en su comunicación el punto de vista de los excluidos y de las víctimas de cada siluación social, y por dar a ese punto de vista un lugar privilegiado en el diálogo. Las víctimas han de ser el norte de la razón comunicativa, precisamente porque son individuos, impedidos en sus más elementales derechos individuales.

Sólo así se podrá corregir esa deformación previa con la cual la razón accede al diálogo, y que convierte lo que debería ser "particularidades que se suman," en "privilegios que se restan." De no ser así, la nueva razón occidental que parece ir gestándose tampoco será una razón comunilaria sino, a lo más, una razón "mayoritaria," que utilizara su poder mayoritario para asentarse sobre un resto de reducidos a la condición de "sin voz" y, por ello, sin razón. Semejante forma de "razón" habrá sustituído la fuerza de la comunicación (que ella misma dice buscar) por la fuerza del número.

$Y$, en este contexto, no resulta casual, sino que constituye una seria advertencia, el que en el primer mundo haya comenzado a hablarse últimamente de la sociedad que llaman "de los dos tercios." Una parte de privilegiados, y otra de suficientemente instalados, se ponen de acuerdo tácitamente para expoliar a otra tercera parte de "sumergidos" o victimas, sobre las cuales se asientan y a las que silencian. El carácter minoritario de este grupo de víctimas (posibilitado tanto por la revolución tecnológica como por la interdependencia del mundo que permite "barrer hacia fuera" otro gran número de víctimas) trastueca radicalmente todos los planteamientos maxistas del siglo pasado, los cuales presuponian la fuerza 
mayoritaria cada vez más creciente de las víctimas. Pero no redime la mentira del individualismo occidental, sino que la hace más cnmascarada y más insuperable.

En cambio, si la razón comunilaria se deja interpelar por ese sentido de "responsabilidad solidaria" (para utilizar el lenguaje de Adela Cortina), el mundo desarrollado podría realizar también la otra crítica (absolutamente necesaria) de su propia noción de progreso y de la "razón instrumental" que la ha engendrado. Por ahl, el primer mundo debería llegar a comprender que no todo lo ya factible es, por eso mismo, ya faciendum: que no todo lo que ya puede hacerse, hay que hacerlo. O que no todo paso material hacia adclante constituye un progreso real en la verdadera dirección humana. Sino que —dada la irreversible unidad $\mathrm{e}$ interdependencia que ya ha conquistado nuestro mundo- todo progreso no universal, no solidario y no atento a la situación de las víctimas del planeta, se convierte necesariamente en un crecimiento unilateral y mostouoso, que deforma al organismo humano y rompe la armonia del cuerpo de la humanidad.

Todas estas consideraciones obligan al primer mundo a una revisión importante del eslogan sacrosanto de los "derechos humanos." En gran parte de la vida del primer mundo, "derechos humanos" no ha significado hasta ahora más que "privilegios individuales." El eslogan debe recuperar su valor en la línea de aquella verdad elemental de Augusto César Sandino: "los derechos de los pobres son más sagrados que los derechos de los poderosos." Y el primer mundo podría fácilmente emparentar esta frase con aquella otra de $\mathrm{N}$. Berdiaeff: "el pan para mí es un problema material; mientras que el pan para mi hermano es un problema espiritual." Este acercamiento permitiría entender la palabra "sagrados" en la frase de Sandino y haría ver que, con ella, nos encontramos ante una verdad que es en sí misma religiosa porque - como la realidad de Dios - sólo pude ser reconocida: no se impone por sf misma puesto que -por hipótesis- los débiles son aquellos que carecen de fuerza hasta para imponer sus derechos más elementales, mientras los poderosos disponen de fuerza y de medios hasta para imponer sus derechos secundarios, o terciarios, o simplemente falsos o enfermizos.

Establecer en concreto esa jerarquización de los derechos humanos ya no es cosa que toque hacer aquí, sino que pertenece al campo de la moral. Pero la teología debe poner de relieve que sólo, en ella podría encontrarse hoy la posible apertura a ese principio comunitario, que necesita el individualismo del primer mundo. Y, personalmente, estoy convencido de que, sin esta profunda revolución, - "conversión," Occidente quedará cada vez más profundamente incapacitado para encontrar algún acceso a Dios, por más que, en sus horas desesperadas, quizá lo busque en evasiones pseudorreligiosas. Se cumplirá así en el primer mundo la clásica sentencia paulina: "se oscureció su insensato corazón y quedaron prisioneros de sus vanas elucubraciones" (Rom 1, 21). Palabras que quizás tienen un desarrollo mucho más concreto en estas otras líneas del Nuevo Testamento, que parecen también un resumen breve de la historia del mundo "ilustrado:" "Sabiendo que nada trajimos a este mundo y nada nos llevaremos de él, aprendamos a contentamos si tenemos qué comer y con qué vestimos. Pues los que quieran 
enriquecerse se precipitan hacia tentaciones y trampas y mil descos irrazonables y funestos, que hunden a los hombres en la ruina y en la perdición. Pues la razón de todos los males es el ansia de dinero. Y algunos, obsesionados por esa ansia, no sólo han acabado apartándose de la fe, sino que se han causado a sí mismos mil sufrimientos" (1Tim 6, 7-10).

El ansia del dinero es lo que ha quedado de la razón y la libertad de la ilustración. Y esta ansia - según el texto citado- parece tener una triple consecuencia: a) la adulteración de la razón humana (que lleva hasta incapacitar para la fe); b) la opresión de los demás hombres (a lośque causa nina y muerte); y c) los mil innecesarios tormentos para uno mismo.

Tras hacer esta advertencia, parece honrado reconocer que, hoy por hoy, son mayores los peligros de degeneración de la nueva razón occidental que las esperanzas de su redención. El horizonte de las víctimas es el más difícil de incorporar para sus verdugos. Pero la teología de la liberación debe saber bien que, en esos brotes de esperanza, es donde tiene ella su verdadero punto de apoyo y su verdadero "hermano en la fe" dentro del primer mundo. De modo que, por ahí, la redención del primer mundo coincidiria realmente con la liberación del tercero.

\section{Para una superación "espiritual" del colectivismo marxista}

Si la situación del área llamada occidental merece ese calificativo de individualismo que es la degeneración de la persona, la situación de los países comunistas, que suelen designarse como países del este, merece el calificativo de colectivismo que es degeneración de la comunidad. O simplemente, y para decirlo con palabras del propio Marx, la situación del este es todavía la de un "comunismo grosero," aunque su imperfección no provenga de la falta de desarrollo de las fuerzas de producción, en la cual Marx situaba esa forma "grosera" del comunismo.

El hecho innegable es que el propio Mara hacía consistir la realización del ser humano en la identidad entre "ser individual y ser genérico." En la forma como Marx concebía la planificación de la economía, ésta no solamente habría de cubrir todas las necesidades verdaderas de todos los miembros del colectivo social, sino que además había de permitir al individuo concreto "ser por la mañana pescador, por la tarde cazador...," según quisiera.

De este sueflo marxiano no ha quedado huella en los países comunistas, aunque un occidental (si quiere ser honrado) haya de reconocer que nos aventajan en la realización de la justicia económica y de la igualdad entre los hombres, así como en la superación del hambre y la miseria más clamorosas. Este importante fracaso debe, naturalmente, ser analizado al nivel de las causas y de los motivos intrahistóricos (al igual que occidente analiza las razones por las que fracasó el proyecto de la ilustración). Pero, además de esas causas y sin interferir en ellas, es hora de suscitar la pregunta acerca del papel que cabe asignar en semejante fracaso a la forma concreta del ateísmo de Marx. Dicho gráftamente, el proyecto de Marx pretendía realizar lo divino negando a Dios. La coincidencia entre el ser 
personal y el ser comunitario (que para Marx era la realización del ser humano, tal como hemos dicho) es para el cristiano la delinición de Dios, y la realización de la "imagen divina" del hombre.

No debe extrafiar que esa pretensión de realizar lo divino negando a Dios fracase al tratar de realizarse históricamente. Marx quizá la creyó posible porque, sin ninguna razón científica y de modo simplemente dogmático, atribuyó a la materia, concebida dialécticamente y en proceso, cualidades divinas. Presentar semejante atribución como úlima palabra de la ciencia y de la filosolía ya no merece el nombre de ateísmo, sino el de superstición. Por eso el ateísmo marxista, al realizarse históricamente, ha tendido siempre a ser un ateísmo "militante," confesional y perseguidor. Y Max Stimer tenía absoluta razón cuando, criticando toda esa forma "supersticiosa" de izquierda hegeliana, afirmaba que en realidad no eran ateos sino "beatos." Beatos de un mito, lo cual es la más supersticiosa de las beaterías. La irritación ya aludida que este calificativo provocaba en K. Marx, y que se refleja en los ataques a Stimer en La Ideología Alemana, es seguramente la mejor prueba de su verdad.

$Y$ estas afirmaciones deben ser mantenidas aunque se reconozca, por orra parte, la genialidad de sus análisis económicos sobre la mentira y la injusticia del capitalismo, e incluso la posibilidad de una ruptura en la trayectoria personal de Marx, que le habrán llevado a abandonar los planteamientos filosóficos de su juventud para limitarse al análisis económico de su madurez. (La lectura cronológica de los textos marxianos sobre la religión, los cuales van reduciéndose en número y tamaño, y pasan de una crítica de la naturaleza de la religión a una crítica de sus funciones socioles en aquel momento histórico, abonaría esa posibilidad de una ruptura). Pero esa posible ruptura en la persona de Marx no se ha reflejado en los sistemas que se reclaman de él.

Por consiguiente, si la crítica al individualismo de occidente la condensábamos antes en la frase citada de N. Berdiaeff ("el pan para mí es un asunto material, pero el pan para mi hermano es un asunto espiritual"), habría que añadir ahora que la critica al colectivismo marxista puede condensarse en la frase evangélica que suele dirigirse al este desde occidente: "no sólo de pan vive el hombre." Prescindimos ahora de si ése es el sentido exacto de la frase en los evangelios, y prescindimos también de si occidente no hace un uso interesado e ideológico de esa verdad, olvidando que el hombre no vive solo de pan, pero sí que vive necesariamente de pan. A pesar de todo, la frase es veraz, y sigue siendo verdad aunque alguien pretenda que se trata de un pan "dialéctico y en proceso" (o precisamente por eso mismo). Y asf, los regímenes comunistas se han encontrado con que, una vez medianamente salisfechas las necesidades humanas más elementales (alimento, vivienda, sanidad y educación), comienzan a surgir en el hombre otro tipo de demandas más espirituales e igualmente poderosas, para las cuales los sistemas comunistas no están preparados en absoluto.

Esto nos remite otra vez a la necesaria clasificación y jerarquización de los "derechos humanos" desde los derechos de los pobres. Ya dije que no era tarea de este 
arlículo realizar esa clasificación; pero sí quisicra llamar la atención sobre uno de esos derechos, casi nunca mencionado ni calalogado: el derecho a ser estimado, a ser reconocido como persona, como sujeto de dignidad y merecedor de afecto. Hasta qué punto esta demanda es elemental, casi primaria, y está inserta en el fondo de cada individuo por pobre que sea (o quizá más cuanto más pobre es), resulta ser un detalle que ha pasado inadvertido, tanto para el materialismo del individualismo occidental, como para el colectivismo del materialismo del este.

Y quizá es en este preciso punto donde la tcología de la liberación pucde jugar su papel, de cara a la superación de ambos sistemas, cosa que Puebla dejó como programa. La vuelta a los pobres ha supuesto antes que nada, para la teología de la liberación, un reconocimienso de los pobres como sujetos, el cual ha llevado incluso al proyecto de su transformación en verdadero sujetos de la sociedad, de la Iglesia y de la teología. Este proyecto puede parecer inviable (y de hecho ha sido discutido por alguno de los mismos teólogos de la liberación, en nombre de la actual situación infrahumana de los pobres, la cual reclamaría primariamente el que sean objeto de la atención y de la dedicación total de los cristianos y de la Iglesia). Pero, sin entrar en esta discusión, cabe decir que el proyecto de la teología de la liberación debe ser mantenido a toda costa, al menos en el sentido en que el Nuevo Testamento habla de anticipaciones de la meta escatólogica ya al seno de la historia, porque "nuestra resurreción con Cristo," en algún sentido "ya ha tenido lugar."

$\mathrm{Y}$ aquí aparece otra vez la importancia de las comunidades de base para la teología latinoamericana, como lugares primarios en los cuales se posibilita esa recuperación de la calidad de sujetos para los pobres. De este modo se percibe también hasta qué punto dichas comunidades no son un "añadido pastoral" o un complemento accidental de la teología latinoamericana, sino que están en la entraffa misma de su reflexión teológica.

Y de este modo también el proyecto de la tcología de la liberación, a la vez que pone del revés la concepción individualisa del primer mundo, la cual convierte al pobre en objeto de explotación, pone tambien del revés la concepción colectivista leninista del segundo mundo, la cual niega al pobre la calidad del sujeto "para sí," obligándole a pasar por la conciencia del partido, y convirtiéndole también en objeto de dirección.

\section{Conclusiones}

Podemos resumir todas estas rellexiones sobre el problema teológico de las relaciones individuo-comunidad con cinco conclusiones enunciadas en forma de tesis.

La persona debe delinirse por su apertura a la comunión y a la trascendencia. El carácter ilimilado de la primera característica la abre a su vez hacia la segunda. Mientras que la pretensión absoluta de la segunda característica fundamenta la primera El hombre es asl ónticamente imagen de Dios, y ontológicamente refe- 
rencia a Dios. Y la cerrazón culpable a csta doble apertura sería el pecado o destrucción de la persona.

De esta primera afirmación se sigue un par de tesis complementarias.

La comunidad debe definirse como comunión de libertades. O con otras palabras: sólo crea comunidad aquello que libremente se entrega. Individuo y comunidad, en su verdad última, no crecen en proporción inversa, sino en proporción directa. Por eso hemos dicho que toda forma de individualismo -en cuanto falsificación de la persona- no realizará comunidad. Y que toda forma de colectivismo -en cuanto falsificación de la comunidad- no realizará a las personas. La existencia humana en la tierra sólo puede scr un caminar, lento e inacabable, hacia la superación de ambos escollos.

Las dos tesis anteriores presuponen, al menos como límite, la identidad entre los conceptos de libertad y amor. Ambos tienen como término antitético el egoísmo, el cual es, a la vez, falsificación de la libertad y destrucción del amor. Si el amor sólo se construye con libertades, hay que añadir también que la libertad sólo se construye en la solidaridad. De ahí la advertencia de Gálatas 5, 13.

Estas dos últimas tesis llevan necesariamente a la doctrina tcológica de la gracia. Sin "el amor de Dios derramado en nuestros corazones por el Espíritu Santo que se nos ha dado" ( $c f$. Rom 5, 5) el hombre aparecería como una pasión, inútil por imposible. Si la fe en cl Espíritu empuja al hombre a afirmar a pesar de todo la posibilidad de esa pasión humana, entonces esa alimnación apunta a Dios como condición de posibilidad de la armonía entre "ser individual y ser genérico."

Desde aquí se comprenden unas célebres palabras de $H$. de Lubac: "no es verdad que el hombre no pueda organizar la tierra sin Dios. Lo que sí es cierto es que, sin Dios, acabará fatalmente organizándola contra el hombre." ${ }^{44}$ Porque sin Dios, la relación individuo-comunidad se ve forzada fatalmente a degradarse, o en un autoritarismo (quizás bien intencionado) que lleva al colectivismo, o en un liberalismo (ya no sé si tan bien intencionado) el cual lleva a las más clamorosas situaciones de injusticia y de muerte.

Finalmente, todo lo anterior lleva también a decir una palabra sobre la Iglesia. El dilema decisivo a la Iglesia ante el mundo es si da testimonio de creer en Dios (trakando de transparentarlo) o si da la impresión de utilizar a Dios en defensa propia. Por eso no es casual que la teología de la liberación (aunque, en sus comienzos, no pensó para nada en este punto) haya sido leida como "la oportunidad de una segunda reforma para la Iglesia" (J. B. Metz).

En efecto, si la Iglesia quiere ser sacramento de esa unidad entre lo individual y lo comunitario que hemos ido persiguiendo a lo largo de este artículo, no le quedará más remcdio que abandonar buena parte de su estructuración societaria actual, para aprender a construirse como "comunidad de comunidades." Semejante tarea es seguramente inagotable y constituye el caminar de la Iglesia por la historia. Por eso los cristianos han de ser profunda y sapiencialmente pacientes 
ante sus deficiencias de realización. Pero ello no impide la percepción evangélica de que el autoritarismo eclesiástico (con su subsiguiente y cómoda confusión entre unidad y uniformidad) ya no puede jusuficarse ni siquiera apelando a la necesidad de conservar un "depósito de verdad." Pues dicho autoritarismo significa ya la mayor falsificación de ese depósito a conservar, dado que la verdad cristiana "se construye en la caridad" (Ef 4, 15). Conviene recordar a este respecto la seria advertencia de $\mathrm{K}$. Rahner, cuando alertaba a la Iglesia para que no cayera en un "colectivismo de los corazones." 5 Si la Iglesia no toma muy en serio esta crítica se privará de credibilidad, y hará inaudibles no sólo wodas sus alusiones a Dios, sino también todas las exhortaciones a la democracia, que a veces trata de dirigir al occidente, y todas las críticas al colectivismo que a veces dirige al este.

Pero esta transformación hacia su verdad sólo será posible el día en que, en la jerarquía de la Iglesia, haya muchos más "maestros del Espíritu," y muchas menos simples "piezas de un engranaje administrativo."

\section{Notas}

1. En este artículo, tal como me lo han pedido, desartollaré un tema central de antropología teológica, para cuyo tratarniento más extenso remito a mi libro Proyecto de hermano. Visión creyense del hombre (Sanlander, 1987). Trato equil de recordar y valorar los datos fundamentales de la fe cristiana de forma más sistemátice para analizar después lo específico de la teología europea y de la teología de la liberación sobre el terma individuo y comunidad.

2. "La incredulidad como problema teológico," en Concillium 6 (1965), 76 y 79.

3. I. Ellacuría, "Las Iglesias latinoamericanas interpelan a la Iglesia española," en Sal Terrae marzo (1982), 219.

4. El drama del humanismo aseo (Madrid 1949), 11.

5. Peligros en el casolicismo actual (Madrid, 1964), 40. 
47. Cfr. E. Hobsbawm, Industry and empire, Balimore, 1969; Id., Europäische Revolusionen, Zurich, 1962.

48. Cfr. R. Soler, Clase y nación en Hispanoamérica, San José, 1977.

49. Citado de S. G. Papcke, "Weltrevolution als Friede," en Welffrieden und Revolution, op. cir., 19.

50. J. Comblin, Théologie de la révolution, op. cis., 139

51. Cfr. E. Dussel, "A cristandade modema frente ao outro, do índio 'rude' ao bom selvagem"' en Caninhos de liberlação latino-americana II, op. cit., 151-160, esp. 151.

52. Cfr. M.M. Smirir, Die Volksreformation des Thomas Münzzer und der grosse Bavernkieg, Berlín, 1956.

53. Cfr. M. Walzer, The Revolution of the Saints. A Study in the Origins of Radical Politics, Londres, 1966.

54. H. Kohn, The Idea of Nationalism, Nueva York, 1958.

55. Cfr. P. Pombeni, Socialismo e cristianesimo (1815-1975), Brescia, 1977.

56. Cfr. G. Hasenhutul, Freiheil in Fesseln. Die Chance der Befreiungs-theologie, OltenFriburgo, 1985; K. Rahner, (Org.), Befreiende Theologie, Mainz, 1977.

57. H. de Souza, Construir a Utopia, Petrópolis, 1987, que nos ha inspirado en estas reflexiones políticas. 